\title{
Blade Vibration on Centrifugal Compressors - Blade Response to Different Excitation Conditions
}

\author{
U. Haupt, K. Bammert, M. Rautenberg \\ Institute for Turbomachinery, University of Hannover, West Germany
}

\begin{abstract}
Results and analysis of blade vibration measurements on a high pressure ratio/high mass flow centrifugal compressor made with strain gages and using multichannel telemetry are described for compressors with 3 different types of vaned diffusers. Considerable high frequency blade excitation and vibration of the shallow region near the impeller outlet were observed. Initial progress to predict this dangerous excitation caused by the diffuser vanes was made with the help of FE computations using a simplified element system consisting of the vibrating zones of a $90^{\circ}$ sector of the impeller. Satisfactory agreement with measured vibration data was achieved.

The influence of rotating stall on blade excitation was investigated using different types of vaned diffusers leading to different numbers of rotating stall zones and variations in the rotational speed of the cells. Blade vibration intensity due to surge in conjunction with variations of the diffuser is also considered.

Holographic interferometry was successfully applied to blade vibration measurements on compressors in operation. The investigation was aimed at studying the occurrence of blade modes and the vibratory behavior of the different blades near the interesting inlet zone. The occurrence of different constellations of blade modes at a resonance point and at an operating point far from resonance was demonstrated.
\end{abstract}

Introduction

Blade vibration is a dangerous effect in the operation of advanced centrifugal compressors, and has to be considered in the stress design. A broad research program has been implemented at the Institute of Turbomachinery, Hannover to study this problem. The work was concentrated on acquiring fundamental information on the intensity of blade vibration during operation of compressors, on excitation mechanisms, and on evaluation of the different excitation phenomena.

A considerable amount of preparatory work, described in detail in $/ 1 /$, was necessary before blade vibration measurements could be made and to make the measurements described in this paper. Blade frequencies, blade modes and the stress distribution of vibrating radial blades in different modes were computed using the FE method. The results obtained were confirmed by vibration tests at rest using strain gages and a sound pickup. Additional vibration tests were carried out to determine the damping properties of the blade and of the whole impeller. An 8-channel telemetry system with an inductive power supply was installed to allow tests on the compressor in operation; the reliability of the telemetry system was demonstrated up to the maximum rotational speed of about $\mathbf{n}=22000 \mathrm{rpm}$.

Initially, blade vibration measurements on operating compressors were carried out to investigate the extent of blade excitation due to the non-uniformity of the flow downstream and upstream of the impeller. Responses of the radial blades to other excitation phenomena are the subject of this paper, which is completed with theoretical investigations of impeller vibrations and additional optical measurements on the operating compressor.

\section{Blade Excitation Due to Diffuser Vanes}

The results of blade vibration measurements on a compressor with a vaneless diffuser demonstrated its influence on blade excitation of the flow range downstream of the impeller. Accordingly, compressors with other common geometrical configurations in this zone, such as diffuser vanes, were also investigated. Blade vibration measurements were carried out on compressors with three different types of vaned diffuser, each with 19 vanes. The location and the vane shapes of these diffusers are shown in Figure 1. Whilst the cambered vane diffuser and the straight channel diffuser have constant blade angles over the channel width, the inlet angles of the twisted diffuser have been matched according to the flow conditions in this zone.

Blade Vibration at Constant Rotational Speed and Various Throttle Valve Positions

Results of blade vibration measu rements at constant 


\section{Compressor with cambered vane twisted straight channel vaned diffuser diffuser diffuser diffuser}

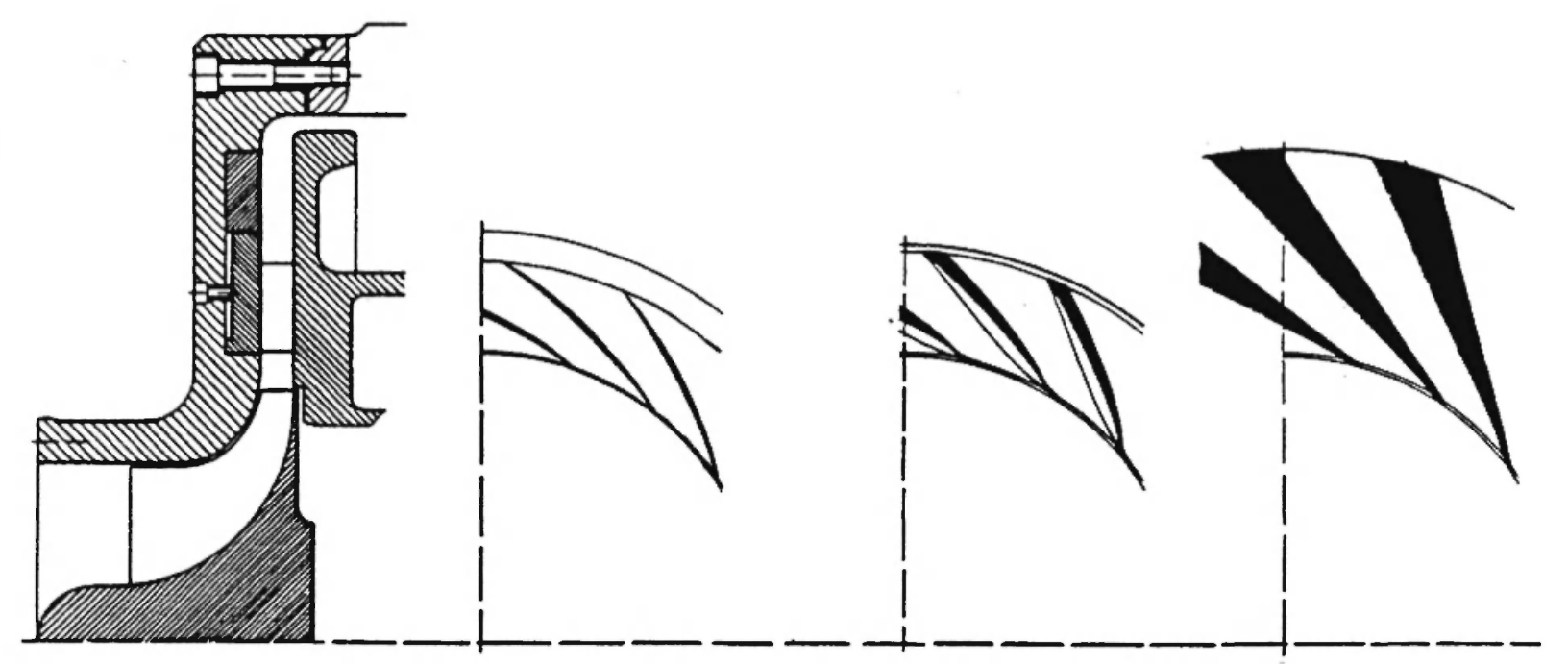

Fig. 1: Shape of the different types of diffuser vanes used in the blade vibration measurements.

rotational speed away from resonance points are shown in Figure 2. The stress amplitudes of one blade are plotted for different vaned diffusers in the compressor chart for radial compressors in Figure 2. A comparison of these results with those obtained on the compressor with the vaneless diffuser documented in $/ 2 /$ only shows little difference.

The use of different vaned diffusers causes slight displacements of the compressor characteristics, especially the surge line and the choke line. At low values of rotational speed, the vibration effects observed for the cambered vane and for the straight channel diffuser were similar to those determined on the compressor with the vaneless diffuser. This indicates an increase of blade excitation at lower values of mass flow due to stall effects in the compressor inlet and stable reverse flow in the inlet tip region, resulting in a decrease of blade vibration. This vibratory behavior could not be observed on the compressor with the twisted diffuser where - away from resonance points - generally lower values of blade vibration stress amplitude were obtained, as for the other two diffuser configurations, too. The use of the twisted diffuser permits operation at higher mass flow rates, and the surge line too is shifted to the right in the compressor chart in comparison to the characteristics for the other two diffusers. For all tested diffuser configurations and at rotational speeds above $\mathrm{n}=12000 \mathrm{rpm}$, only a slight increase of blade excitation was observed before compressor surge took place. The occurrence of rotating stall directly adjacent to the surge line, which is the reason for the increase of blade vibration in this zone mainly in the speed range of $n=10000-14600 \mathrm{rpm}$ and visible in Figure 2, was considered in a special investigation described below.

Blade Vibration with Increasing Rotational Speed at Constant Throttle Valve Position

Very interesting results of blade vibration measurements for two blades are plotted in Figure 3, obtained with the compressor with the cambered vane diffuser. As indicated in $/ 2 /$ and $/ 3 /$, significant resonance peaks of blade No. 1 are observable at $n=$ $5400 \mathrm{rpm}$; this is due to an excitation of the first blade mode by the diffuser vanes. Very unusual and unexpected is the resonance vibration near $n=18000$ rpm with maximum stress amplitudes of nearly $\epsilon \approx$ $1.0 \mathrm{~mm} / \mathrm{m}$, equivalent to a material strain of $\sigma=70$ $\mathrm{N} / \mathrm{mm}$. Results of measurements in the speed range of the occurrence of this resonance are shown in Figure 4 for 6 blades, each displaying very different resonance characteristics. While the strong blade excitation demonstrated in Figure 3 can only be observed for the blades No. 7 and No. 1, blades No. 2 and 3 show 

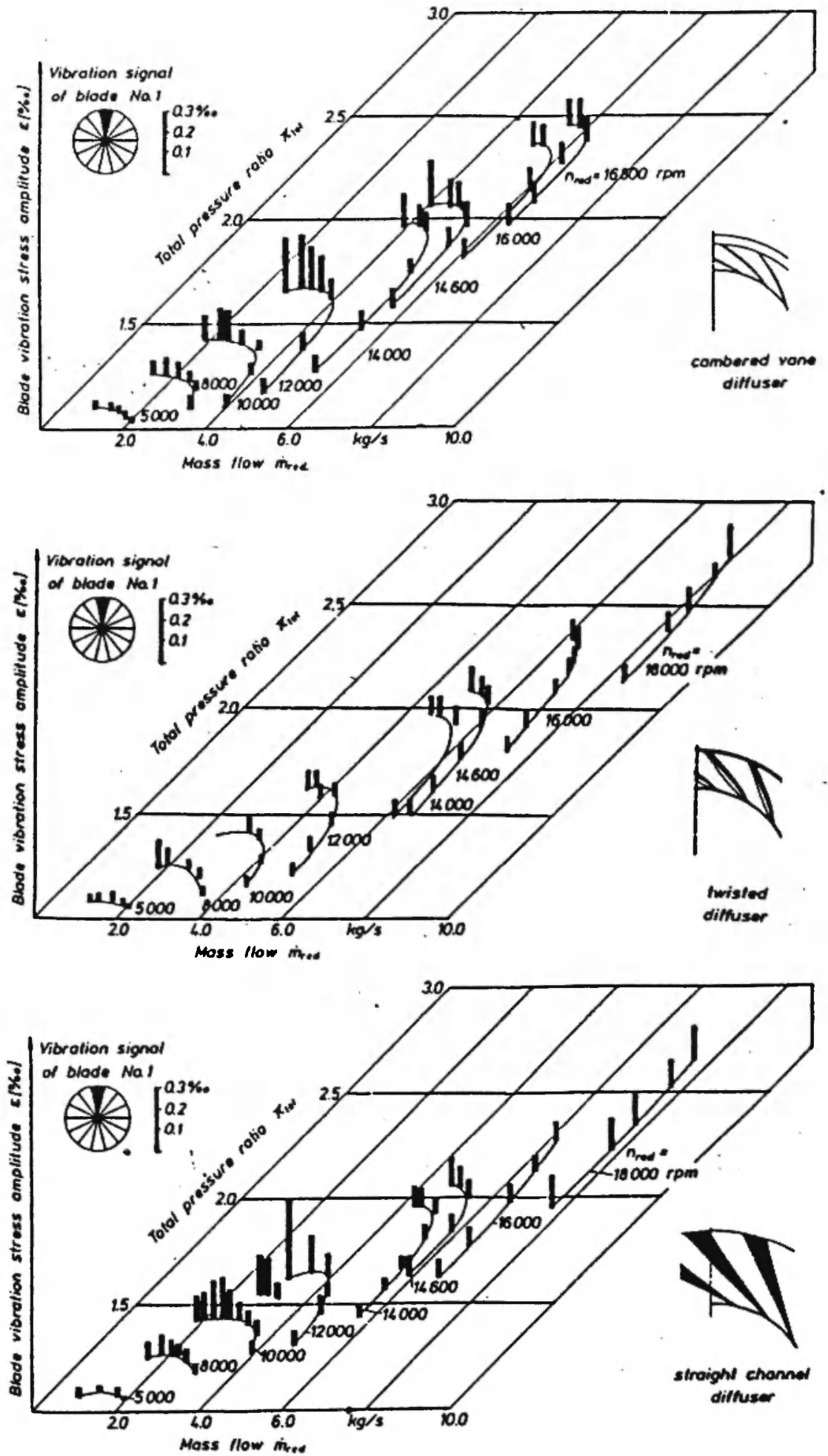

Fig. 2: Results of blade vibration measurements at constant rotational speed with different types of vaned diffuser.

maximum resonance peaks of lower intensity at a slightly higher rotational speed. The reason for this excitation was discovered by analysis of the blade vibration signals plotted in a Campbell diagram, as shown for blade No. 1 in Figure 5. This diagram indicates that the strong peaks shown in Figures 3 and 4 are due to excitation of relatively high blade frequencies which are not usually taken into conside- 


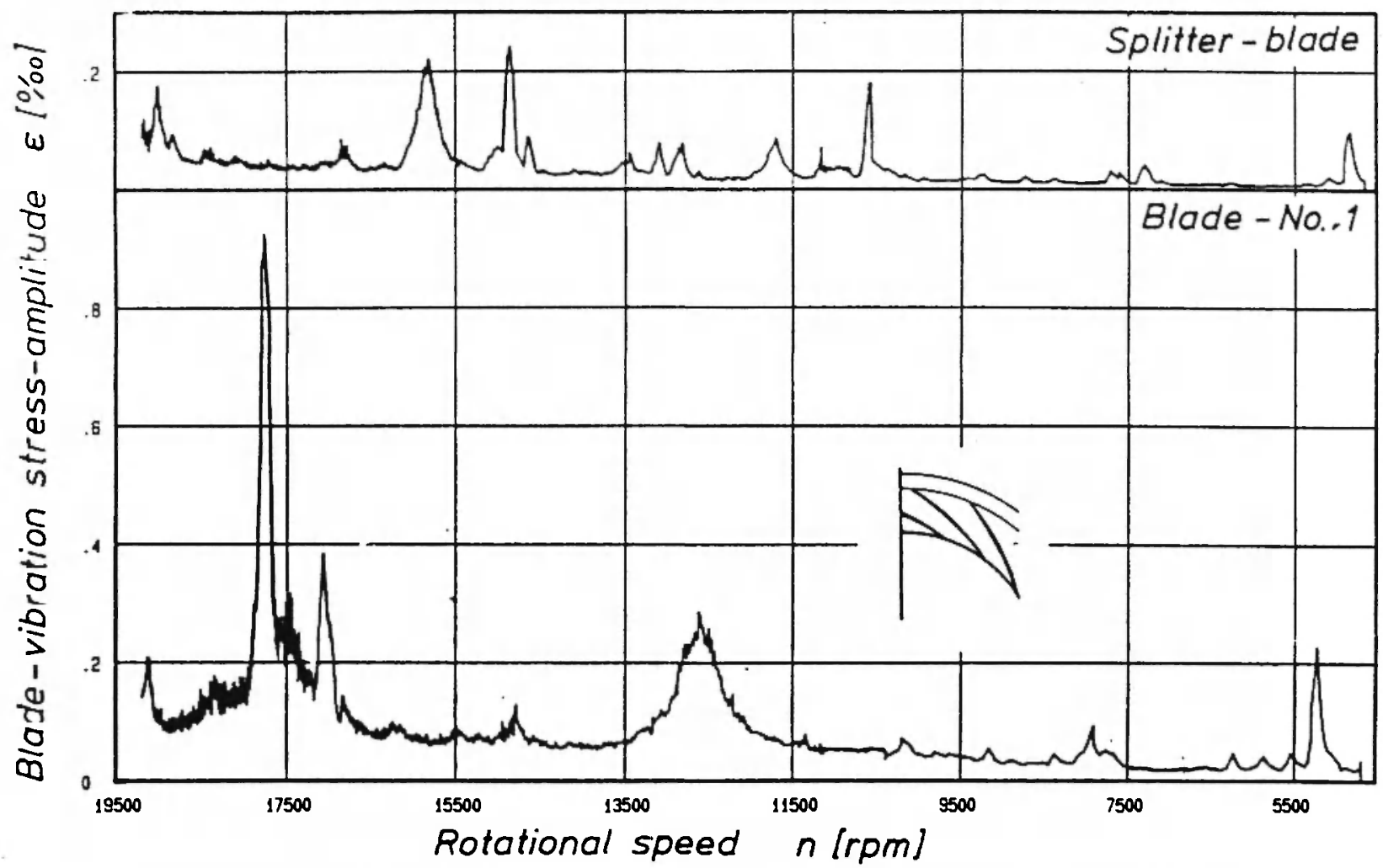

Fig. 3: Blade vibration stress amplitude for 2 blades in the whole speed range of a compressor with a vaned diffuser. Operating line near choke line. Diffuser: 19 cambered vanes.

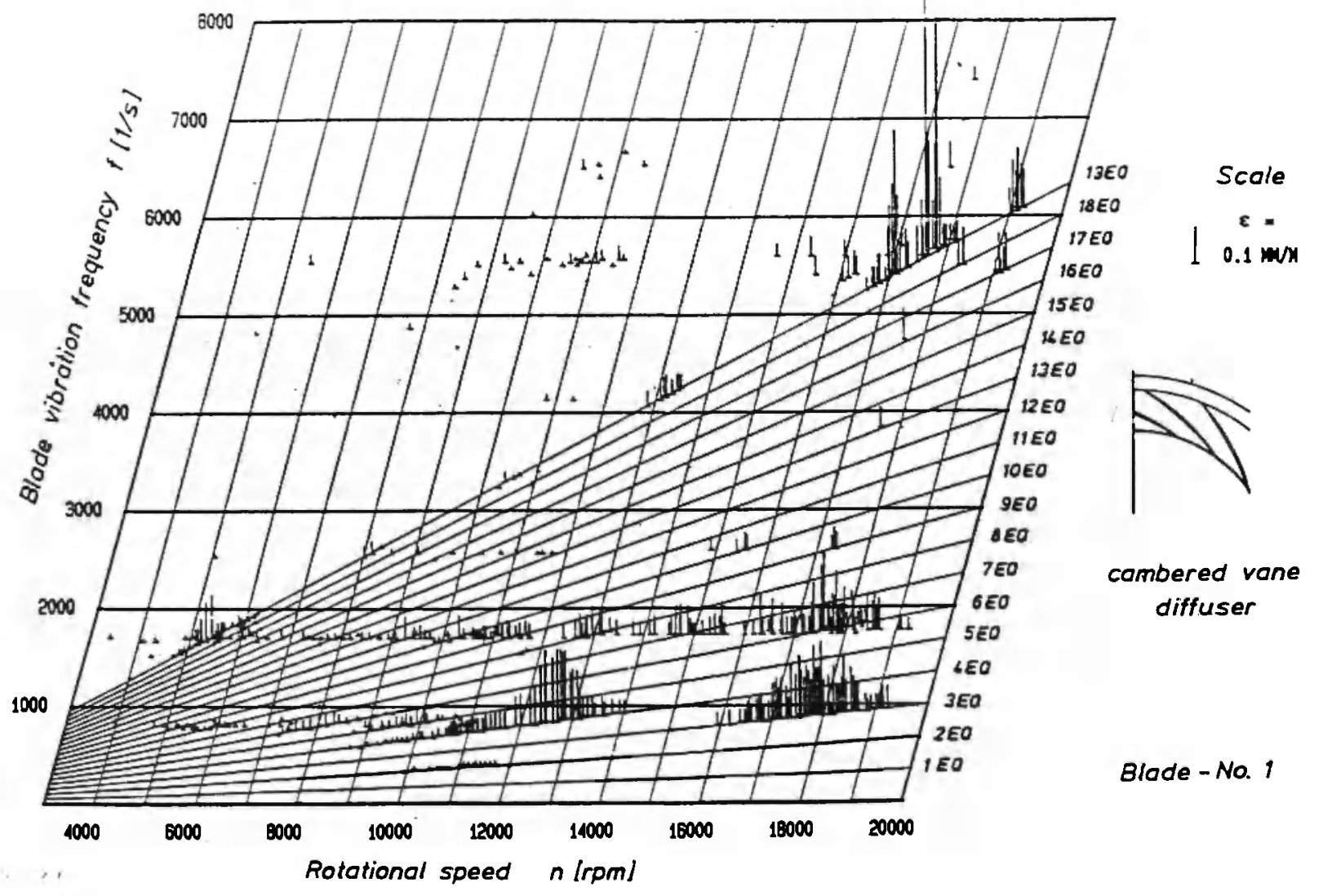

Fig. 4: Campbell diagram for one blade (blade No. 1). 
Blade Na

Channel No.

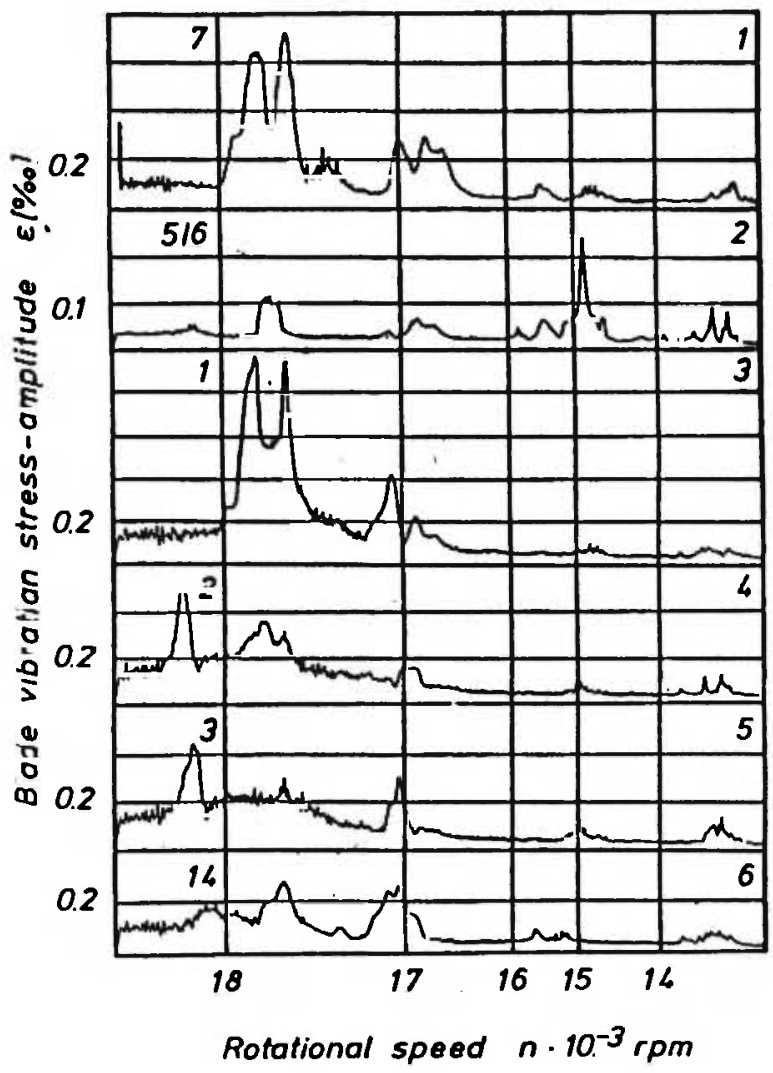

Fig. 5: Blade vibration at decreasing rotational speed and constant throttle valve position on a compressor with a vaned diffuser (19 vanes), $n=20000-$ $16000 \mathrm{rpm}$.

ration in the stress design of radial blades. A vibration test at rest using holographic interferometry was carried out by taking an interferogram of the impeller excited at $f \approx 5500 \mathrm{~Hz}$ in order to get more information on the causes of this high blade frequency excitation. In this interferogram, shown in Figure 6, the stripes that are very close to each other correspond to large displacements during the vibrational motion, and vice versa. With respect to blade vibration, two different modes can be observed; FE calculations and a comparison of the mode shapes showed that they were the VIII and IX blade modes. The main indication of this interferogram is the obvious occurrence of strong vibrations of the shallow ring section at the impeller outlet, with large displacements between the different blades. Obviously, the excitation of blade frequencies in the mentioned range is mainly due to an excitation of a natural frequency of the impeller ring section. The blades take part in this

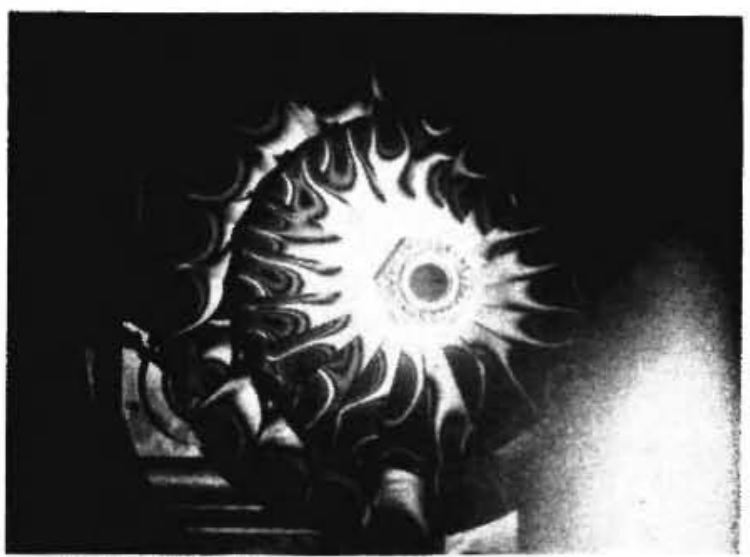

Fig. 6: Holographic interferogram of the radial impeller at rest excited to vibration in a laboratory test. $\mathrm{f}=$ $5500 \mathrm{~Hz}$.

vibration in the same frequency range and are excited at the blade outlet by the motion of the ring section. It has already been mentioned that mode shapes of the blades in high frequency ranges are characterized by strong displacements of the blade outlet zone, which in the present case is due to interactions between blade and ring regions.

\section{Investigation of Blade Flutter}

Blade flutter has turned out to be a very dangerous vibrational phenomenon on axial compressor signified by low values of blade thickness. Measurements with respect to this problem on radial compressors with thin blades should indicate whether blade flutter will be observable on radial blades too when the blade thickness is reduced. When running the compressor in operating ranges where flutter is known from axial compressor research as described in $/ 4 /$, no clear indications of blade flutter resulted.

Additional measurements concerning this problem were carried out by recording the pressure fluctuations in the impeller region while the compressor was operating at a high frequency blade resonance point (Figs. 3 and 4). Results described in $/ 3 /$ indicated no influence of the vibrating blades on the flow characteristics and none of the interactions between flow and blade which are necessary for the occurrence of flutter.

\section{Blade Excitation Due to Rotating Stall Cells}

Experience with axial compressors has shown that 
blade excitation due to rotating stall cells is a serious and dangerous problem. This effect requires special consideration in the case of compressors operating in off-design points, such as jet engines, where resonances between blade frequencies and the rotational speed of the cells can cause blade failures. Despite considerable efforts being made in this field today, it is not yet possible to exactly predict the number of cells in a compressor and the rotational speed required to avoid resonances. Only experimental experience is available.

Reducing the blade thickness of radial impellers may also lead to the problem of blade resonance excitation due to rotating stall cells. Blade vibration and flow measurements were carried out with the aim of acquiring more information on this problem; the first results are published in $/ 5 /$.

The occurrence of rotating stall can be detected with semiconductor pressure probes installed in the compressor wall. The typical results shown in Figure 7 were obtained from a compressor with a vaneless diffuser operating in continuous rotating stall conditions. One blade vibration signal is plotted together with three pressure signals from probes at different peripheral positions; this permits determination of the number of rotating cells, while the rotational speed of the cells can be obtained in conjunction with the trigger signal.

Interesting results were obtained at higher speeds, where the occurrence of rotating stall was only observed for small time intervals. The extent of blade excitation due to this phenomenon is shown in Figure 8 for 6 blades, and results of pressure measurements are presented for one time interval of the occurrence of rotating stall.

Measurements carried out at all operation points of the compressor where plain rotating stall could be detected, are illustrated graphically in Figure 9. It should be mentioned that all results characterize operating conditions away from resonance points between blade frequencies and the rotational speed of the cells. In the measurements no indications of resonance were observed; resonance may occur when the blade frequency, the rotational speed of the cells and the number of cells coincide.

The results in Figure 9 show the occurrence of rotating stall at very different rotational speed ranges, according to the type of diffuser used. Very different conditions were also obtained with regard to the

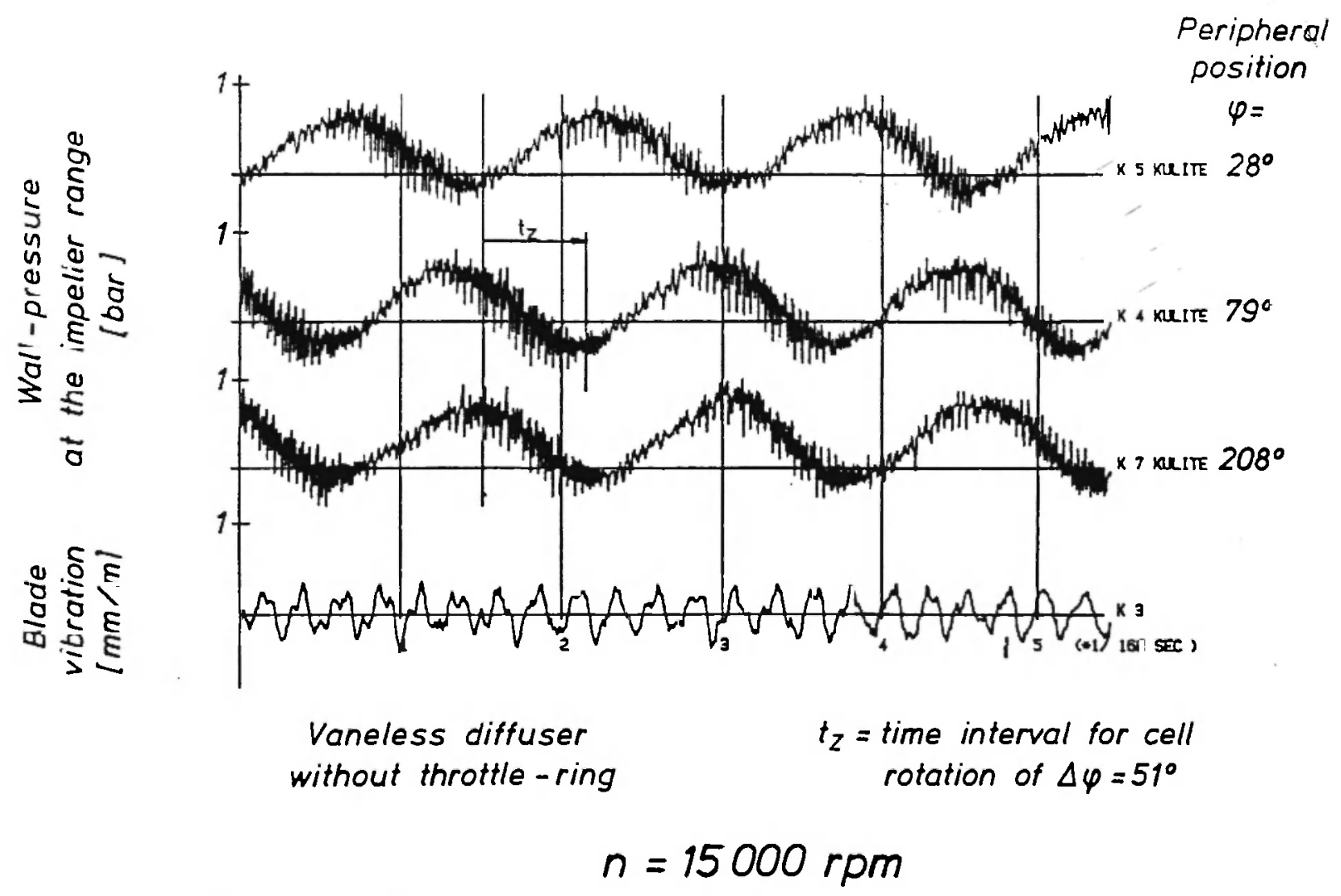

Fig. 7: Blade vibration excited by rotating stall cells; determination of the number of rotating zones. 

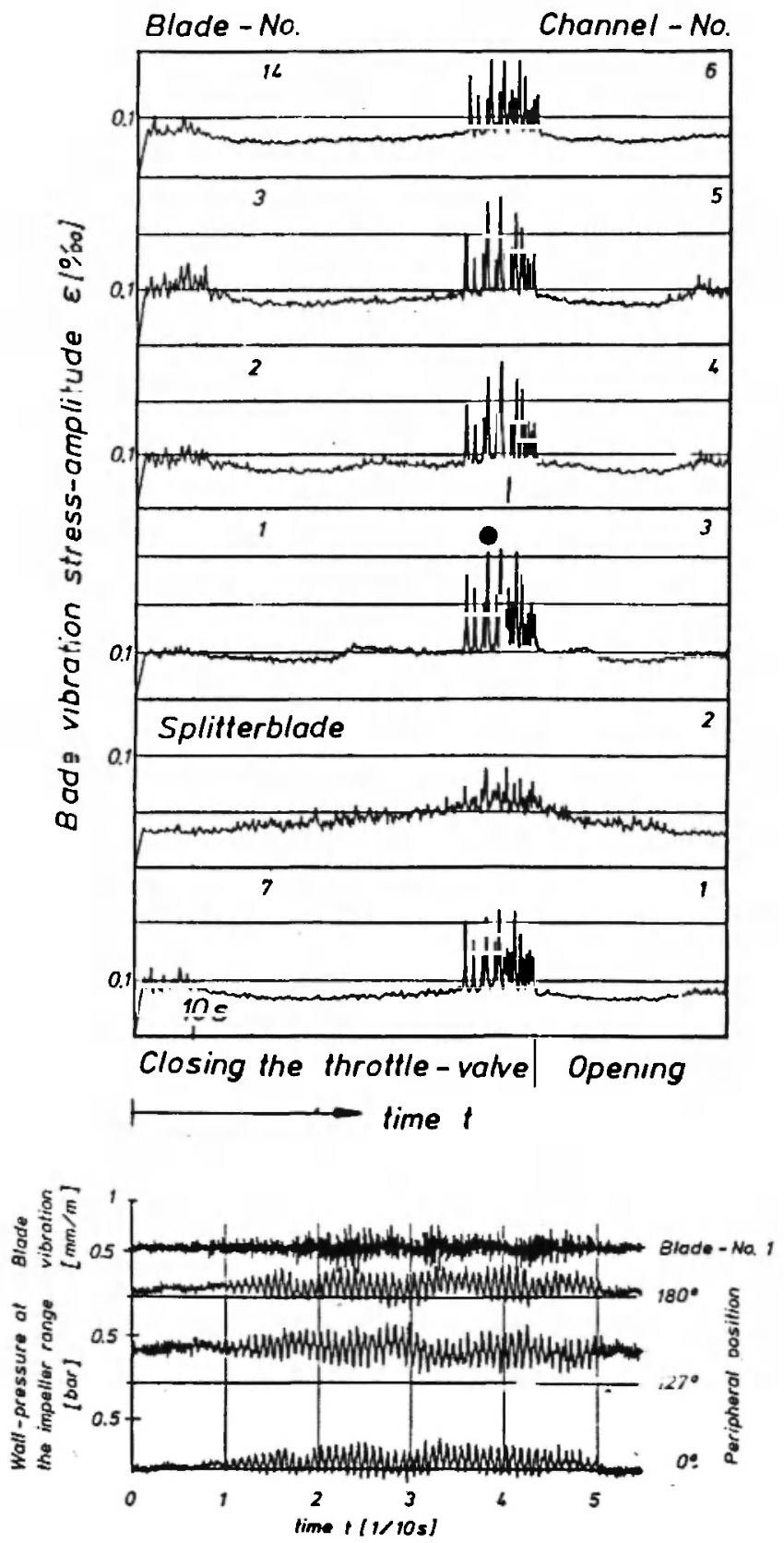

Blode vibration and wall pressure in the mange of the occurrence of rotating stall at

Fig. 8: Blade vibration due to rotation stall cells on a radial compressor with vaneless diffuser without throttle ring at $\mathbf{n}=16000 \mathrm{rpm}$.

number of cells and the rotational speed of the cells. It can be concluded that the type of diffuser considerably influences the appearance and the characteristics of rotating stall. Rotating stall often results in an increase of the blade vibration amplitude to a value approximately twice as high as that before

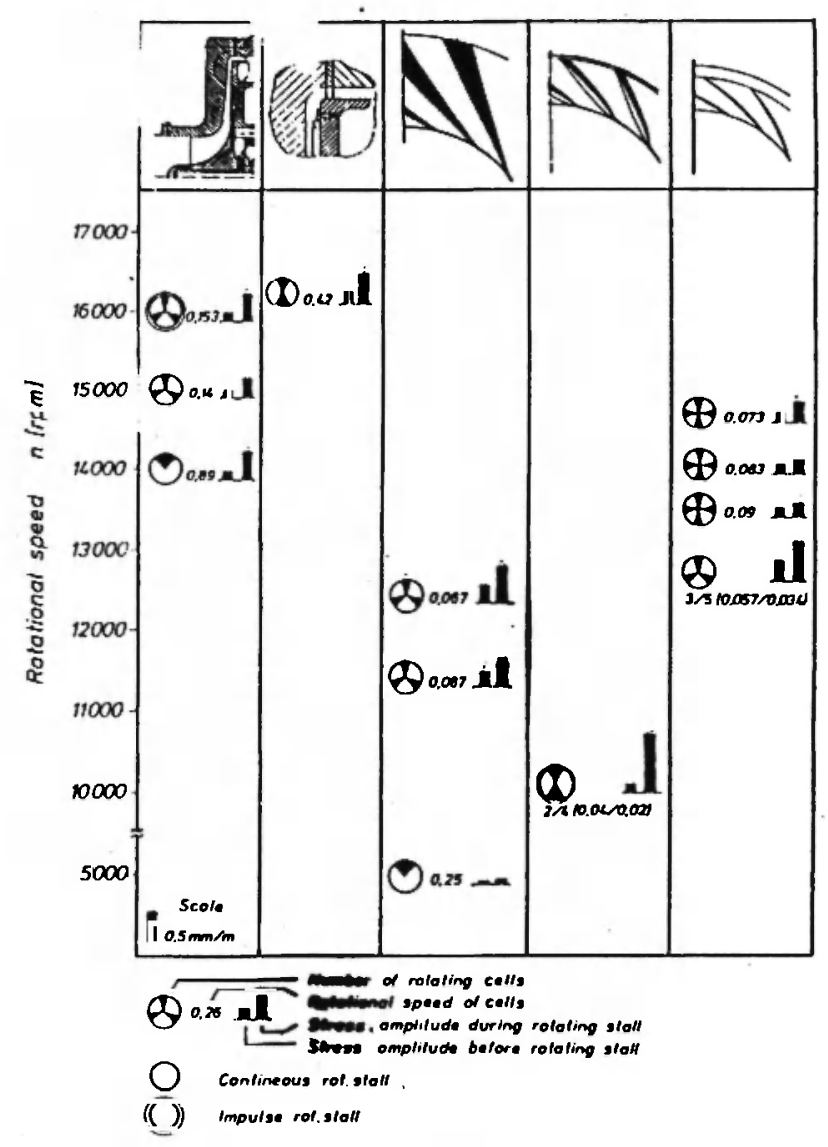

Fig. 9: Results of blade vibration measurements in the range of occurrence of rotating stall; comparison of results for different types of diffuser.

it occurs. The increase was slightly higher for the vaneless diffuser; blade vibration due to rotating stall on the compressor with the twisted diffuser is an exception, showing considerable blade excitation at $\mathbf{n}$ $\approx 10000 \mathrm{rpm}$. Above this rotational speed, no rotating stall was obtained before compressor surge occurred.

\section{Blade Excitation De to Surge}

A detailed brestigation was carried out with respect to the degree of danger due to compressor surge. This was accomplished by a detailed analysis of blade vibration signals with simultaneous analysis of signals of different semiconductor pressure probes in order to investigate the flow and thus the cause of the blade excitation. The first results are contained in $/ 2$ / and a detailed analysis is made in $/ 5 /$.

Surge tests with blade vibration and flow measurements were initially carried out on a compressor with a vaneless diffuser. Figure 10 contains an analysis of 


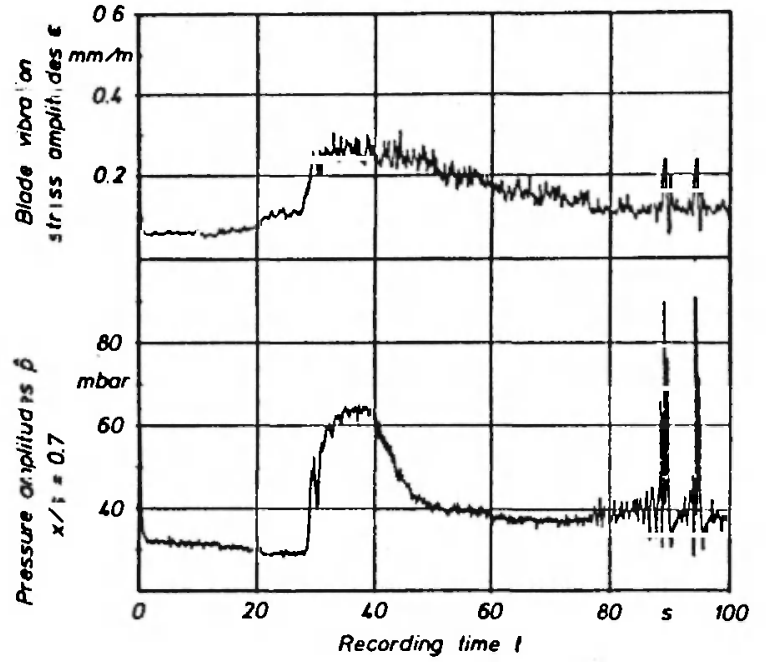

Centrifugal Compressor with vaneless diffuser $n=14000 \mathrm{rpm}$

Fig. 10: Blade vibration and wall pressure when throttling a compressor with vaneless diffuser from the choke to the surge line.

this data for $n=14000 \mathrm{rpm}$, and shows basically the same characteristics as those observed at lower rotational speeds. The signals show that the intensity of blade excitation in the operating range of stalled inlet flow rises to higher values than those present during surge. For the compressor with a vaneless diffuser it can be concluded that surge is not a dangerous cause of blade vibration up to this rotational speed. Pressure amplitudes in Figure 10, recorded from measuring points in the impeller region, show great similarity to the slope of the blade vibration signal, and demonstrate the correlation between the vibrating blade and the cause of excitation. Surge tests at higher rotational speeds were not carried out due to safety reasons.

A more detailed consideration of flow and blade vibration during surge is contained in $\mid 5 /$, which deals mainly with an investigation of one surge cycle. The signals from the pressure probes and blade vibration data were analysed by digitizing the values and were jointly evaluated. Pressure signals measured in compressors with vaneless and with vaned diffusers showed strong peaks at the beginning and at the end of a surge cycle, i.e., during the times when the flow direction changes. Figure 11 shows that this effect is also present in the blade vibration signals for the time interval of one surge cycle. Obviously, much stronger blade vibration occurs during surge with a vaned

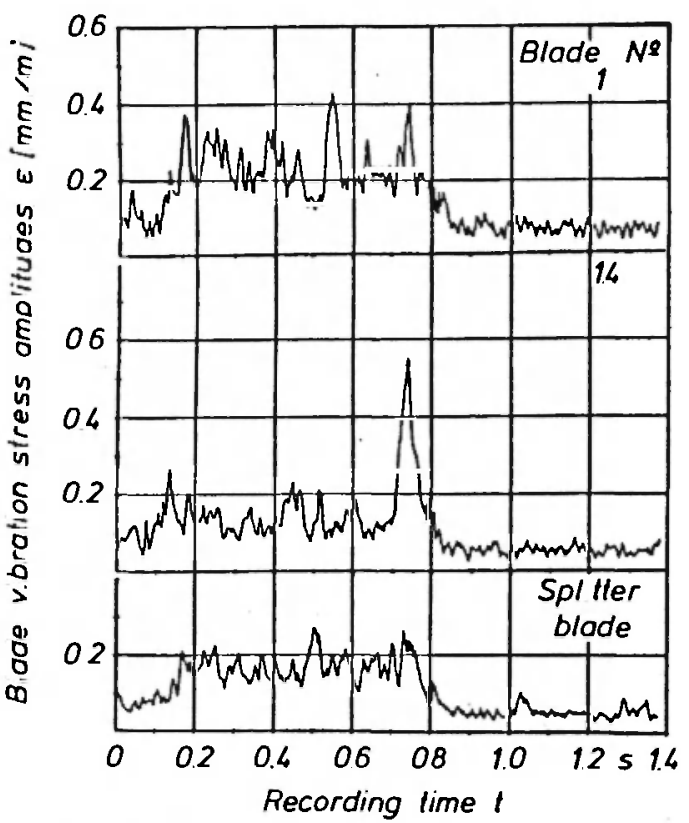

Centrifugal Compressor with Vaneless diffuser $n-16000 \mathrm{rpm}$

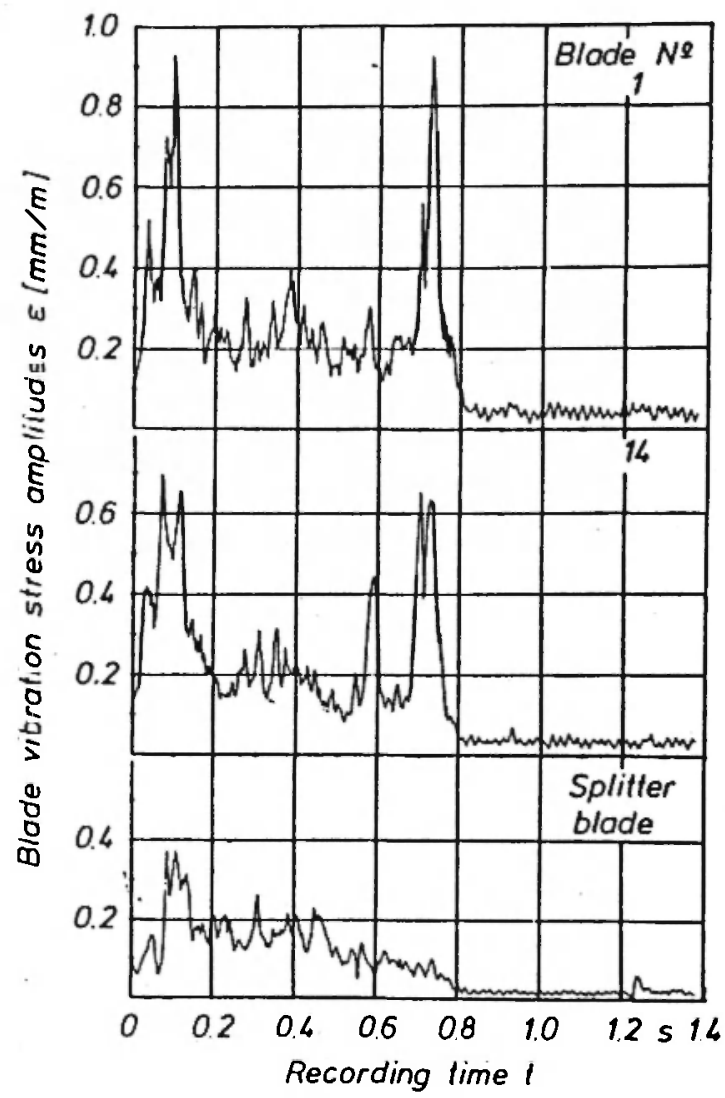

Centrifugal Compressor with Vaned diffuser $n=14000 \mathrm{rpm}$

Fig. 11: Comparison of blade vibration amplitudes during one surge cycle at $n=14000 \mathrm{rpm}$ for compressors with vaneless and vaned diffusers. 
diffuser than with a vaneless diffuser. The maximum stress obtained for blade No. 1 of $\epsilon \approx 1.0 \mathrm{~mm} / \mathrm{m}$ at $\mathrm{n}$ $=14000 \mathrm{rpm}$ shows that compressor surge leads to dangerous excitation of blade vibration at compressor operating speeds above $n=14000 \mathrm{rpm}$.

\section{FE Calculations with Respect to Vibration of the Whole Radial Impeller}

A detailed analysis of high frequency blade excitation of the diffuser vanes of a compressor in operation was accomplished by means of holographic interferometric measurements made on an impeller at rest. Figure 1 shows typical results.

The results show strong interactions between blade vibration in this frequency range and vibration of the impeller disc in the outlet zone, this seeming to be the dominant effect. Concerning stress design of highly loaded radial impellers, it was considered necessary to predict these dangerous effects in order to avoid failure. This was the reason for continuing the FE calculations for the whole impeller. The results are described in $/ 6 /$, while other methods are suggested in $/ 7 /$ and $/ 8 /$.

Following a lot of parameter studies for a convenient element distribution with a reduced element number, a $90^{\circ}$ section of a 20 bladed impeller with 18-element blades and the outer portion of the back plate was chosen (Figure 12). The calculated vibratory behavior of this structure confirmed several important vibrational effects observed previously for the operating compressor and in tests on the impeller at rest. The results demonstrated the great importance of the contribution of the impeller disc to vibration. The influence on the amplitude and phase constellations was particularly clear at higher frequency ranges.

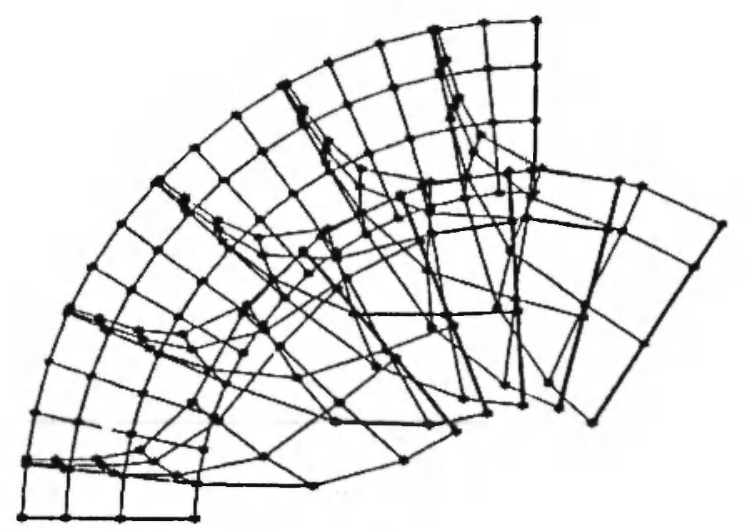

Fig. 12: Element structure for a quadrant sector of a radial impeller; view to the inlet range.
Figure 13 shows typical constellations of blade vibration which were often observed in vibration tests at rest. The three blade elements of the impeller inlet which are plotted represent a resonance configuration with vibration in the first blade mode. Whilst Figures $a$ and $b$ show in-phase and countercurrent blade phase vibration, Figure $\mathrm{c}$ represents a most interesting case
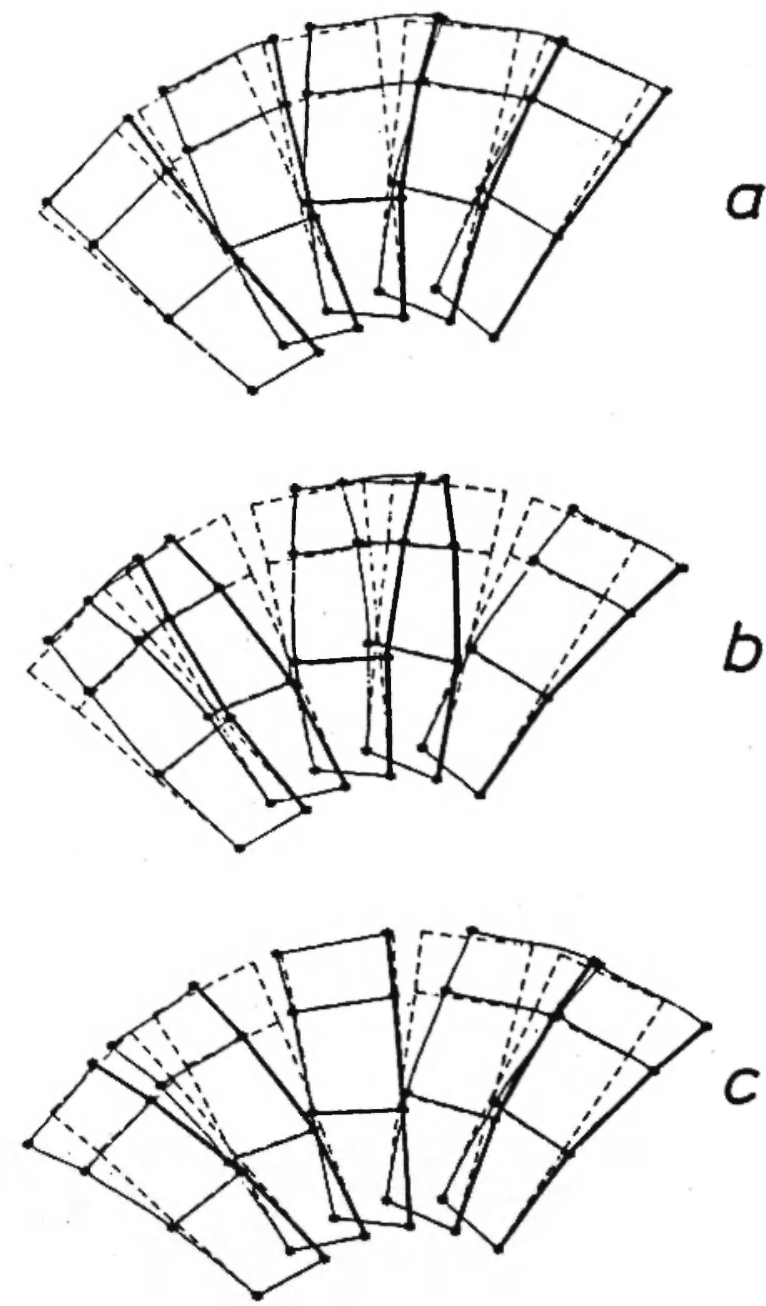

Fig. 13: Vibration constellations of the blade inlets in the first blade mode a) in-phase vibration; b) countercurrent phase vibration; c) one blade nearly at rest.

often observed in vibration tests at rest and during operation of the compressor. Here, one blade is nearly at rest while the others are vibrating with large amplitudes. These effects were usually explained by different blade thicknesses resulting in different sensitivity to blade excitation. Results of this calculation demonstrate that interactions between the blades, and especially due to different phase angles, are the 
reason for the non-uniform resonance behavior of the different blades.

The different higher resonance mode shapes of the impeller system shown in Figure 12 are plotted in Figure 14, where the blade structure has been neglected in the plots. These results were compared with the corresponding mode shapes of the ring section without blades. Figure 6 shows that, in the $90^{\circ}$ impeller section, the vibration modes of the ring section are dominant. It is interesting to observe the superposition of the XI disc mode to all modes of the system shown in Figure 14, representing a mode shape - according to the result in Figure 6 - with node-lines at the blade roots and maximum displacements between the blades. A resonance frequency of

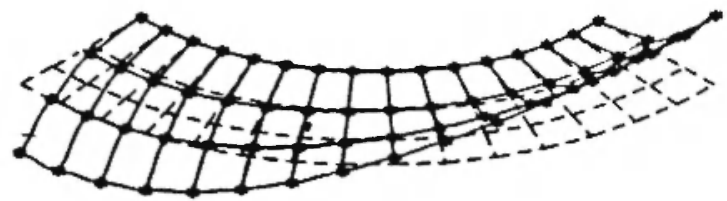

III.

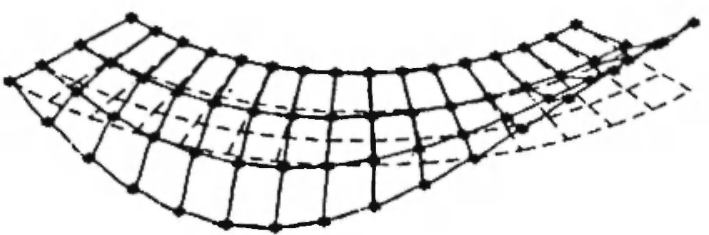

IV.

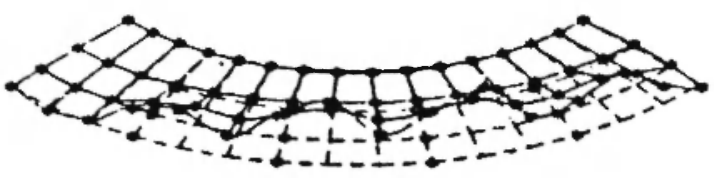

The Use of Holographic Interferometry for Blade Vibration Measurements

One fundamental disadvantage of strain gage measurements is the fact that information is obtained from one point only. Different stress signals from two

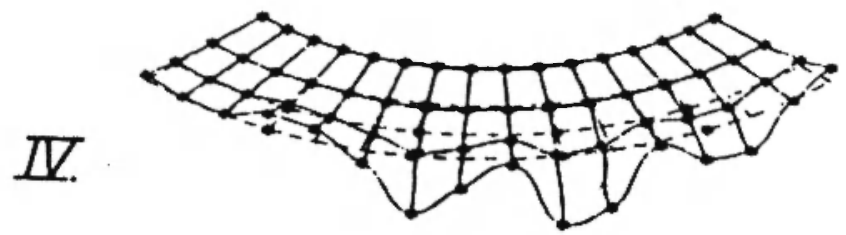

VI

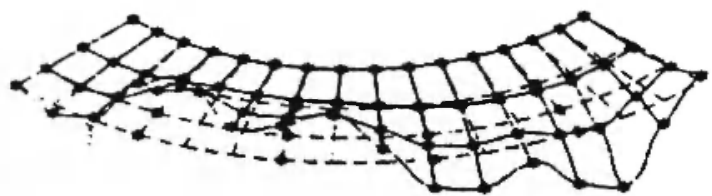

XI

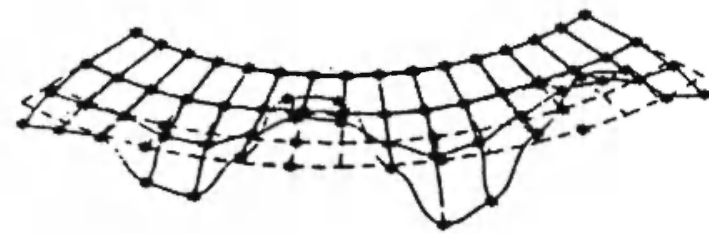

Vibration modes of ring-section of impeller

Fig. 14: Vibration of the system impeller/disc and blades showing the displacement of the outlet zone of the disc. 
adjacent blades at the same measuring point do not necessarily mean that the stresses are characteristic for these two blades. It has already been mentioned above that coupling effects between all of the blades of an impeller influence the mode shapes, and so the stress maxima will probably be found at different points on the blade. With respect to this phenomenon, an investigation of an impeller at rest would not be satisfactory because essential ambient conditions such as the centrifugal force and the flow would not be taken into account.

Cooperation with the "Bremer Institut für angewandte Strahitechnik (BIAS)" enabled us to take one step forward in solving this problem.

An optical method to measure vibrations in rotating systems was developed $/ 9 /$, and its reliability was proved in laboratory tests. The method holographic interferometry - was used in conjunction with a rotating prism. The optical measurement method itself is described in $/ 10,11,12 /$, and results of radial blade vibration measurements are contained in $/ 13,14,15 /$. It was necessary to find out whether the method would be applicable under the rough operating conditions of a highly loaded centrifugal compressor with heat, oil and powerful vibrations of the whole machine.
Figure 15 shows the principle setup of the holographic measurement system as used on one of the radial compressor test rigs. Holographic interferometry is combined with a rotating prism, a derotator, which eliminates the rotating motion of the impeller. The main problem in applying this method to our machine was to mount all the optical components in a way which isolates vibration despite the considerable motion of the operating compressor. Further, it was very difficult to ensure that the prism rotated exactly at the rotational speed of the impeller. This was achieved by scanning 200 markers from the reverse of the impeller disc with a photo cell using an optical fiber.

The inlet tube was removed for the first fundamental investigations of the compressor with a 20 bladed impeller with an outer diameter of $290 \mathrm{~mm}$, because the method used employs some optical components in the rotating axis. The whole compressor including the measurement setup was covered by a black plastic foil to keep out light during the double pulse exposure. A vibration signal telemetered from one blade ensured that the compressor was driven at an operating range where blade excitation would occur. Initial results are documented in $/ 2 /$. Figure 16 shows an interferogram, an analysis of the blade

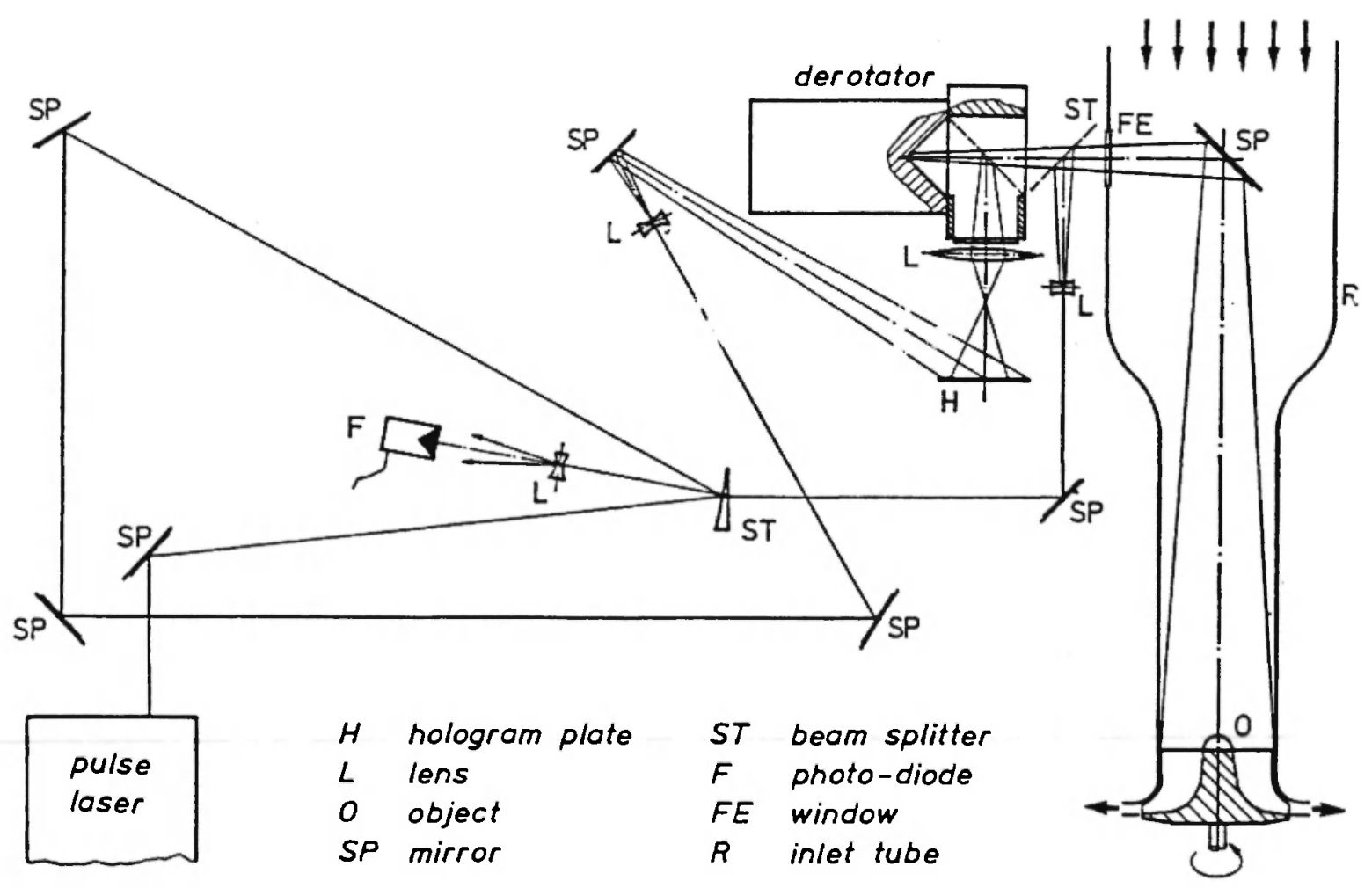

Fig. 15: Holographic set up for the blade vibration measurements. 


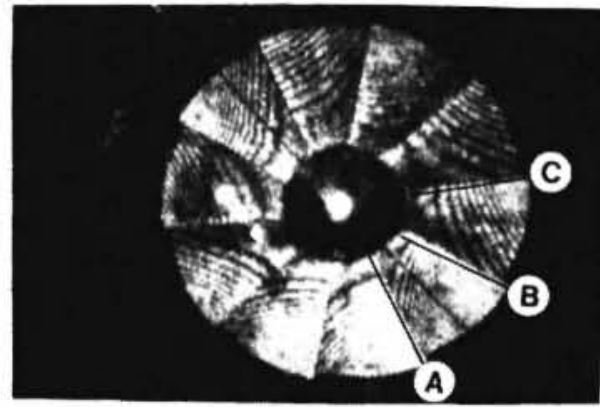

interferogrom of the radial impeller blades
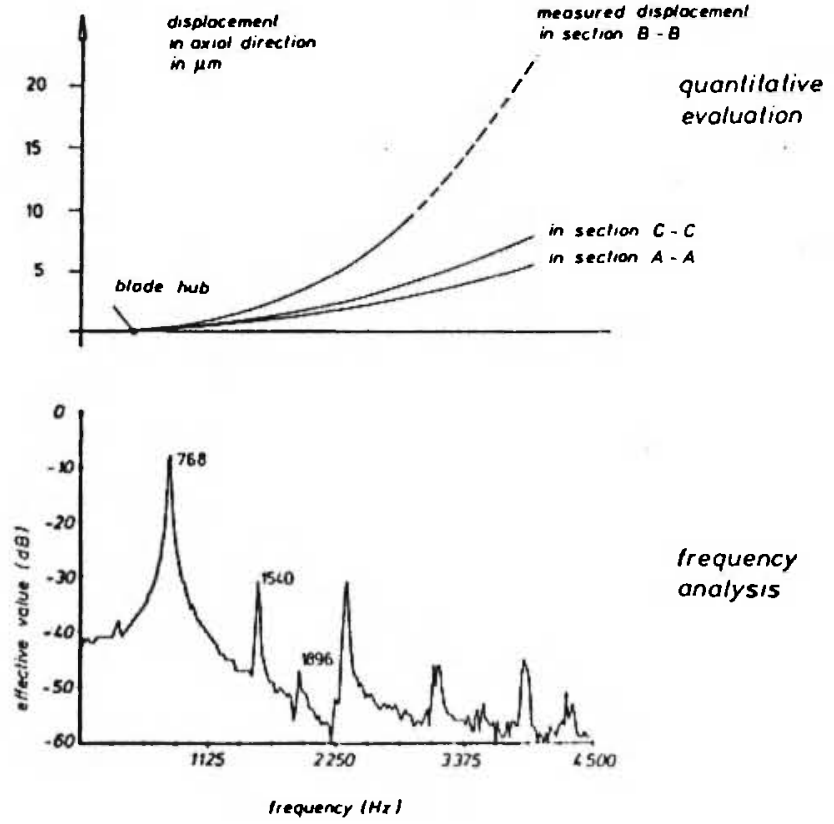

Fig. 16: Results of optical blade vibration measurements at $\mathrm{n}=3000 \mathrm{rpm}$.

displacement, and a frequency analysis at $\mathrm{n}=3000$ $\mathrm{rpm}$, where all blades vibrate in the first mode excited by the teeth of one of the gear wheels in the gear box. The interferogram shows the same mode shape for all blades, with different displacements due to interactions of the blades; this turned out to be characteristic for a coupled system (see Figure 13). Obviously, at a resonance point the influence of these interactions on blade vibration amplitudes depends upon the phase angles of the vibrating blades. They do not influence the mode shape and thus the stress distribution during vibration.

Similar investigations with a duration between pulses of $50 \mu$ s were carried out up to a rotational speed of $n=8000 \mathrm{rpm}$, where the measurements were limited by the considerable suction force of the inlet flow. Thus, an adaptation of the method to a closed inlet was desired, and, in fact, this is necessary for realistic flow and excitation conditions. A new inlet tube as shown in /2/ was manufactured with a glass window; the latter had parallel faces for the entry of the laser beam. To turn the beam into the rotating axis, a mirror was attached to a holder mounted in the inlet tube with the help of three aerodynamic carrier blades. Another window was provided on the top of the tube for the purpose of mirror adjustment.

Corresponding results confirming the observations in Figure 16 are shown in Figure 17 at $\mathrm{n}=2950 \mathrm{rpm}$, where the start of resonance is represented by the vibration of only some blades. The interferogram in Figure 18, taken at $\mathrm{n}=10000 \mathrm{rpm}$, shows uniform resonance vibration of the first blade mode, while Figure 19 represents a resonance of the second blade mode with some variations in the mode shape; the latter were also obtained in a corresponding vibration test at rest.

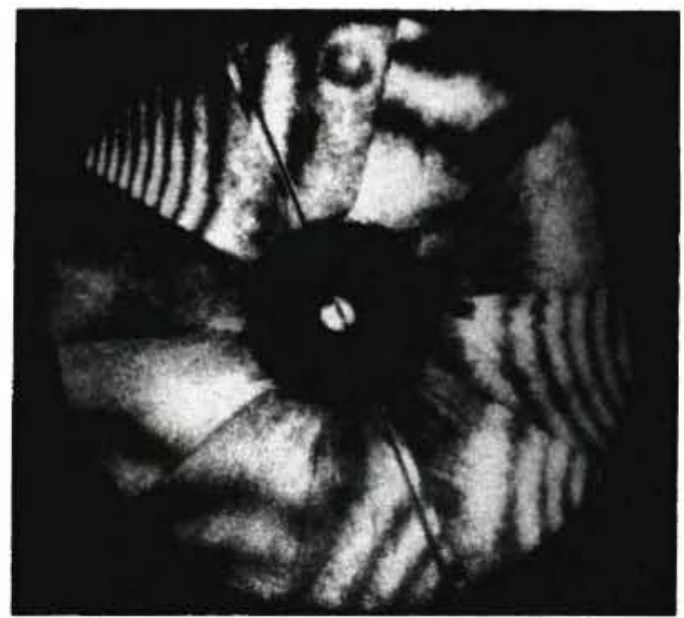

Fig. 17: Interferogram of the impeller at $n=2950 \mathrm{rpm}$.

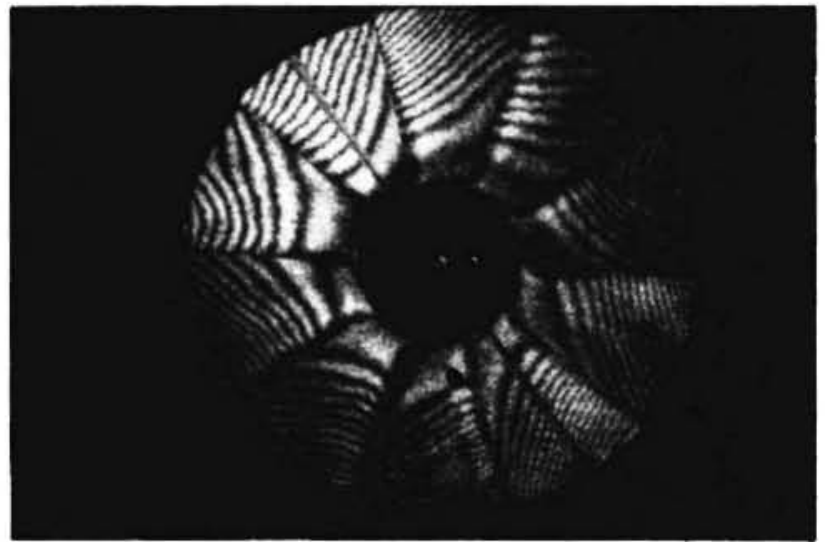

Fig. 18: Interferogram of the impeller at $n=10000 \mathrm{rpm}$ 


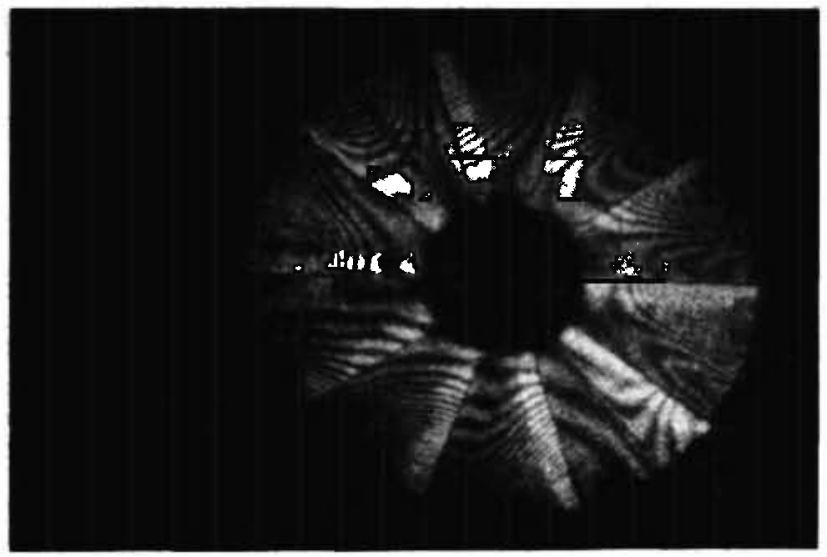

Fig. 19: Interferogram of the impeller at $n=11900 \mathrm{rpm}$.

Characteristic mode shapes of blade vibration away from resonance conditions are shown in Figure 20 , where the blades are vibrating in various modes. While some blades show mode patterns similar to the I, II and III mode, other blades are vibrating in mixed modes of low natural blade frequencies. Corresponding results, which were obtained up to the maximum rotational speed of the compressor of $n=20500 \mathrm{rpm}$, are documented in $/ 2 /$.

\section{Conclusions}

Results of an investigation of blade vibration on a high pressure ratio/high mass flow centrifugal compressor with thin blades are described. Blade excitation was shown to be dependent upon the type of the diffuser used. Experiments on compressors with different types of vaned diffusers showed less occurrences of the blade vibration due to stall effects in the inlet tip zone as it was detected on compressors with a vaneless diffuser. Strong blade vibration excited by the diffuser vanes was obtained at $\mathrm{n} \approx$ $17500 \mathrm{rpm}$; this was shown to be mainly due to vibration of the impeller outlet section. Blade flutter, which is a dangerous effect on axial compressors, was not observed during the investigation.

Blade excitation due to rotating stall cells was investigated for different diffusers. The occurrence of rotating stall turned out to be very much dependent on the diffuser used. Excitation of blade vibration was measured at amplitudes about twice those present before stall occurred. A further increase of blade excitation was obtained for the compressor

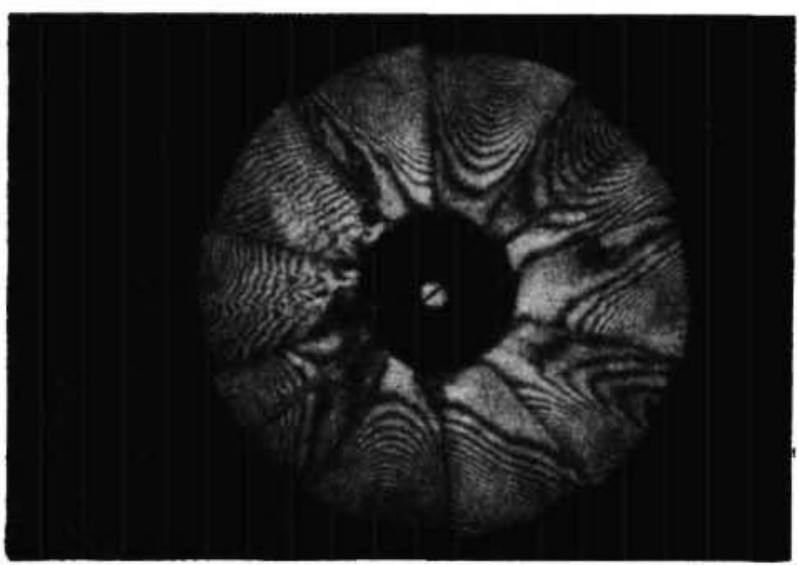

Fig. 20: Interferogram of the impeller at $n=7350 \mathrm{rpm}$.

with the twisted diffuser at $\mathbf{n}=8000 \mathrm{rpm}$. Compressor surge was investigated via blade vibration and flow measurements with respect to the danger of blade excitation. It can be concluded that blade vibration increases in short time intervals at the beginning and at the end of a surge cycle, and that blade excitation during surge was much stronger for the compressor with the vaned diffuser than for the vaneless diffuser configuration.

- Results of an FE calculation of a $90^{\circ}$ sector of the impeller showed some important aspects of the vibratory interactions between the blades and the impeller ring section at the outlet. The resonance frequency of the ring section in a blade mode with mode lines at the blade roots and maximum displacements between the blades was obtained at $\mathrm{f} \approx 5500$ $\mathrm{Hz}$; this is the range of occurrence of strong blade vibrations due to diffuser vane excitation.

Results of optical measurements using the method of holographic interferometry with a rotating prism to eliminate the rotational motion of the impeller are presented. In resonance operation, blade modes were obtained in the pure natural modes without variations of the patterns in the interferograms. Interactions between the blades themselves can be detected by the different vibration amplitudes due to phase angle effects. Operation of the compressor away from resonance is signified by the simultaneous occurrence of mixed blade modes and different natural modes.

\section{Acknowledgement}

The research described in this paper was funded by 
the German Research Association (DFG) and the Forschungsvereinigung Verbrennungskraftmaschinen e. V. (FVV). The authors would like to thank them for their support.

The help of Dr. Jäger in the preparation of the work, of Dr. Kreitlow and Dipl.-Ing. Geldmacher in the optical investigations, of Dr. Kassens and Dipl.-Ing. Hasemann in the signal analysis and of Mr. v. Leuder and Mr. Tanneberg in the experiments is also gratefully acknowledged.

\section{References}

1. U. Haupt, K. Bammert, and M. Rautenberg, "Blade Vibration on Centrifugal Compressors Fundamental Considerations and Initial Measurements", Int. Gas Turbine Conference of the ASME, Houston, Texas, 1985.

2. U. Haupt and M. Rautenberg, "Blade Vibration Measurements on Centrifugal Compressors by Means of Telemetry and Holographic Interferometry". Journal of Engineering for Power, ASME, Paper No. 83-GT-131, Int. Gas Turbine Conference of the ASME, Phoenix, Arizona, 1983.

3. U. Haupt and M. Rautenberg, "Investigation of the Flow in a Radial Compressor and its Excitation Effect of Blade Vibration". Proceedings of the 1984 Intersociety Energy Conversion Engineering Conference, San Francisco, August 1984.

4. A.A. Mikolajczak, L.E. Arnoldi, L.E. Snyder, and H. Stargardter, "Advances in Fan and Compressor Blade Flutter Analysis and Predictions". J. Aircraft, Vol. 12, No. 4, April 1975.

5. U. Haupt and M. Rautenberg, "Blade Vibration on Radial Impellers Excited by Rotating StallCells and During Surge," Paper 83-Tokyo-IGTC124, 1983 International Tokyo Gas Turbine Congress, Tokyo, October 1983.

6. U. Haupt, M. Rautenberg, and U. Schmoch, "Beitrag zur Schwingungsberechnung von voll- ständigen Radialverdichterlaufrảdern mit Hilfe der Finite-Element-Methode." Konstruktion 36 (1984) H. 9.

7. S.W. Mak and M. Botman, "Substructures Analysis of Impeller Vibration Modes," ASME, Paper No. 75-DET-112, 1975.

8. P.S. Kuo and K.S. Collinge, "Structural Analysis of a Gas Turbine Impeller using Finite-Element and Holographic Techniques", AGARD CP-248, 1979.

9. H. Kohler, "Holographisch-Interferometrische Messtechnik", Technische Messen 1980, Heft 2, S. 59-69; Heft 3, s. 83-92.

10. K.A. Stetson, "The Use of an Image Derotator in Hologram Interferometry and Speckle Photography of Rotating Objects", Exp. Mech. 19 (1978)2, 67-73.

11. H.G. Leis and F.W. Leipold, "Kombination der holografischen Interferometrie mit der DMSMesstechnik zur Spannungsanalyse", Technisches Messen 49 (1982), Heft 718, S. 271-276.

12. M.A. Beeck and H. Kreitlow, "Conditions and Examinations of Vibration Analysis of Rotating Blades with the Help of the Holographic Interferometry", Proceedings of the Laser 77-OptoElectronics Conference, 1977.

13. M.A. Beeck, H. Kreitlow, and W.F. Fagan, "Einsatz eines Reflexions-Bild-Derotators zur holografischen Schwingungsanalyse an rotierenden Objekten", messen + prüfen/automatik (1980), 12, 889.891.

14. J. Geldmacher, H. Kreitlow, M.A. Beeck, and W.F. Fagan, "Schwingungsmessung an rotierenden Bauteilen unter Betriebsbedingungen mit einem Bild-Derotator", Proceedings Laser 81, Springer Verlag.

15. H. Kreitlow, J. Geldmacher, and W. Jueptner, "Entwicklung neuer Verfahren zur holografischen Schwingungsmessung an rotierenden Bauteilen", Proceedings Laser 81 , Springer Verlag. 